\title{
Reliability analysis of marine risers with narrow and long corrosion defects under combined loads
}

\author{
Hu Xianwei ${ }^{1,3}$, Zhou Canfeng ${ }^{2}$, Duan Menglan ${ }^{1 *}$ and An Chen ${ }^{1}$ \\ ${ }^{1}$ Offshore Oil and Gas Research Center, China University of Petroleum, Beijing 102249, China \\ ${ }^{2}$ Research Center of Energy Engineering Advanced Joining Technology, Beijing Institute of Petrochemical Technology, \\ Beijing 102617, China \\ ${ }^{3}$ China National Oil \& Gas Exploration and Development Corporation, Beijing 100034, China
}

(C) China University of Petroleum (Beijing) and Springer-Verlag Berlin Heidelberg 2014

\begin{abstract}
A marine riser, one of the most important components of offshore oil/gas transportation, needs to be designed to eliminate the risks caused by complex ocean environments, platform displacement and internal corrosion, etc. In this study, a new analytical-numerical assessment approach is proposed in order to quantitatively investigate the reliability of internally corroded risers under combined loads including axial tension and internal pressure. First, an analytical solution of the limit state function of intact risers under combined loads is obtained, which is further modified by the non-dimensional corrosion depth $(d /$ $t$ ) for the risers with a narrow and long corrosion defect. The relationship between $d / t$ and limited internal pressure is obtained by finite element analysis and nonlinear regression. Through an advanced first-order reliability method (HL-RF) algorithm, reliability analysis is performed to obtain the failure probability, the reliability index and the sensitivity. These results are further verified by Monte-Carlo importance sampling. The proposed approach of reliability analysis provides an accurate and effective way to estimate the reliability of marine risers with narrow and long corrosion defects under combined loads.
\end{abstract}

Key words: Marine riser, corrosion defect, combined loads, reliability calculation, reliability verification

\section{Introduction}

Marine risers, connecting subsea flowlines to floating production facilities, are important components for deepwater oil and gas development and transportation. However, severe marine environments (including waves, currents, high pressures and temperatures), platform displacement and internal corrosion can lead to serious damage and degradation of the risers. The structural performance of internally corroded risers should be given more attention, since corrosion defects will not only reduce the pipe-wall thickness, but also introduce difficulties in analysis due to the uncertainty associated with the rate of corrosion and the location of its occurrence.

Some studies related to corrosion reliability of submarine pipelines are generally reviewed. Burst pressure of submarine pipelines was systematically studied in some common-used codes, such as ASME B31G (ASME, 2009), DNV-RP-F101 (DNV, 2004), API-579-1/ASME FFS-1 (API, 2009), BS-7910 (BS, 1999) and SHELL92 (Kiefner and Vieth, 1989), etc. Pressurized pipelines with localized corrosion (Ahammed and Melchers, 1996) were previously studied, obtaining a probabilistic limit state model, and reliability is

*Corresponding author. email: mlduan@cup.edu.cn

Received January 19, 2013 further estimated through an advanced first-order secondmoment method. Failure probability of pipelines with active corrosion defects over time (Caleyo et al, 2002) was also estimated through the first-order second-moment method and Monte Carlo simulation. Moreover, a series of small-scale experiments and finite element analyses were employed to analyze the effect of corrosion defects on the burst pressure of pipelines (Netto et al, 2005), the result of which was employed by Teixeira et al (2008) to perform reliability analysis. Additionally, reliability-based assessment of the residual stress effect was employed to analyze underground pipelines under combined effects of active corrosion and residual stress (Amirat et al, 2006), concluding that residual stress largely increased failure probability. As multiple active corrosion defects and stochastic internal pressure have a great influence on the reliability of corroded pipelines, Zhou (2010) proposed a methodology to analyze system reliability and concluded that spatial variability of internal pressure, initial defect size and defect growth rate greatly influenced system reliability. In addition, a new probabilistic physicsof-failure model was developed to determine the temperature and stress dependency of dynamic pit depth growth (Nuhi et al, 2011), being of great importance to analyze the reliability of degradation effects of pitting corrosion in carbon steel pipes. However, the studies of the effects of internal corrosion defects on marine risers have not been reported so far. 
In order to perform a quantitative analysis of a marine riser with a narrow and long corrosion defect under combined loads, a new analytical-numerical assessment approach is proposed in this work. Specifically, an analytical solution of limit pressure of intact risers under internal pressure and axial force is carried out. The expression of limit pressure of corroded risers is obtained based on the limit pressure of intact risers and its finite element analysis. Finally, the reliability index and failure probability are calculated by an advanced first-order reliability method (HL-RF), and the results are further verified by Monte-Carlo importance sampling (MCIS).

\section{Limit state analysis}

In order to analyze reliability of marine risers with narrow and long corrosion defects under combined loads, it is of great importance to build up the limit state functions. In terms of a corroded riser, as shown in Fig. 1, D denotes the outer diameter of the riser, $t$ denotes the wall-thickness, $L$ denotes the corrosion length, $d$ denotes the corrosion depth, $a$ denotes the half of the corrosion angle. The following assumptions are related to the establishment of limit state function.

- The wall of the riser is thin $(t<<L)$.

- The material of risers is incompressible under large plastic deformation.

- The stress-strain relationship of the material is powerlaw hardening, given as:

$$
\sigma=K \varepsilon^{n}
$$

where $\sigma$ is stress; $\varepsilon$ is strain; $K$ is strengthening coefficient; $n$ is strengthening index.

- Moment can be neglected since only the straight section of the riser is considered in this work. To demonstrate this point, finite element analysis (FEA) is performed as shown in Appendix A. The results of FEA suggests that the maximum von Mises stress of the corroded riser under internal pressure and axial force is $465 \mathrm{MPa}$, and the maximum von Mises stress of the corroded riser under internal pressure, axial force and bending moment is $466 \mathrm{MPa}$. That is to say, the influencing factor of bending moment over von Mises stress is $0.13 \%$, which can be ignored.

- The defect is narrow and long enough, in other words, $\alpha$ is small and $L \geq \sqrt{20 D t}$.

\subsection{Intact riser under axial force and internal pressure}

In terms of the intact riser under axial force and internal pressure, the stress can be obtained from the equilibrium equation.

$$
\begin{aligned}
& \sigma_{\mathrm{h}}=\frac{p\left(D^{*}-t^{*}\right)}{2 t^{*}} \\
& \sigma_{1}=\frac{p\left(D^{*}-t^{*}\right)}{4 t^{*}}-\frac{F_{\mathrm{a}}}{\pi t^{*}\left(D^{*}-t^{*}\right)}
\end{aligned}
$$

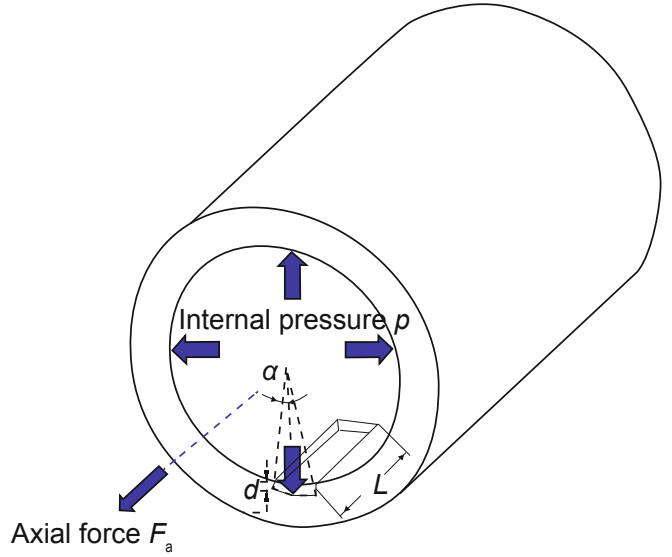

Fig. 1 Internal corrosion defect of a riser

$$
\sigma_{\mathrm{r}}=0
$$

where $\sigma_{\mathrm{h}}$ is the hoop stress; $\sigma_{1}$ is the axial stress; $\sigma_{\mathrm{r}}$ is the radial stress; $D^{*}$ is the outer diameter of the deformed riser; $t^{*}$ is the wall-thickness of the deformed riser; $p$ is the internal pressure; and $F_{\mathrm{a}}$ is the axial force (positive when in compression, and negative when in tension).

Based on the von Mises criterion, the equivalent stress $\left(\sigma_{\mathrm{e}}\right)$ and strain $\left(\varepsilon_{\mathrm{e}}\right)$ can be calculated.

$$
\begin{aligned}
& \sigma_{\mathrm{e}}=\left(\frac{3 p^{2}\left(D^{*}-t^{*}\right)^{2}}{16\left(t^{*}\right)^{2}}+\frac{F_{\mathrm{a}}^{2}}{\pi^{2}\left(t^{*}\right)^{2}\left(D^{*}-t^{*}\right)^{2}}\right)^{\frac{1}{2}} \\
& \varepsilon_{\mathrm{e}}=\frac{2}{\sqrt{3}} \varepsilon_{\mathrm{h}}
\end{aligned}
$$

As the strain is finite, the following equations (Maes et al, 2007) are available.

$$
\begin{aligned}
& \varepsilon_{\mathrm{h}}=\ln \left(\frac{D^{*}-t^{*}}{D-t}\right) \\
& \varepsilon_{\mathrm{r}}=\ln \left(\frac{t^{*}}{t}\right)
\end{aligned}
$$

The expression of internal pressure $(p)$ can be obtained through Eqs. (1)-(5).

$$
p=\frac{4 \mathrm{e}^{-\sqrt{3} \varepsilon_{\mathrm{e}}} \sqrt{\pi^{2} t^{2} K^{2} \varepsilon_{\mathrm{e}}^{2 n}(D-t)^{2}-F_{\mathrm{a}}^{2}}}{\sqrt{3} \pi(D-t)^{2}}
$$

When the internal pressure reaches its limit, the partial derivative of internal pressure with respect to equivalent strain $\left(\varepsilon_{\mathrm{e}}\right)$ equals zero. Accordingly, the equivalent strain is obtained.

$$
\varepsilon_{\mathrm{e}}=n / \sqrt{3}
$$

When the engineering stress reaches the tensile strength $\left(\sigma_{\mathrm{u}}\right)$, necking occurs in the pipeline, satisfying $\left.\frac{\mathrm{d} \sigma}{\mathrm{d} \varepsilon}\right|_{\sigma_{\mathrm{u}}, \varepsilon_{\mathrm{u}}}=0$. 
Using the relationship between the engineering stress/strain and the real ones (Zhu and Leis, 2004), the strengthening coefficient $(K)$ can be obtained.

$$
K=\sigma_{\mathrm{u}}\left(\frac{\varepsilon}{n}\right)^{n}
$$

Combination of Eqs. (6-8) gives the burst pressure of the intact pipeline, $p_{\text {limit }}$.

$$
p_{\text {limit }}=\frac{4 \mathrm{e}^{-n} \sqrt{3^{-n} \mathrm{e}^{2 n} \pi^{2} t^{2} \sigma_{\mathrm{u}}^{2}(D-t)^{2}-F_{\mathrm{a}}^{2}}}{\sqrt{3} \pi(D-t)^{2}}
$$

\subsection{Corroded riser under axial force and internal pressure}

For a narrow and long defect induced by internal corrosion, the corrosion length is too long to exert any influence on the limit pressure. Based on research reported by Chen et al (2008), the corrosion depth and length are two sensitive geometrical factors of the limit pressure of the corroded riser, while the corrosion width is less sensitive. Moreover, the corrosion width is determined by the half corrosion angle $\alpha$, which is small in this study. Accordingly, the influencing factor of corrosion width can be appropriately set as $1-\alpha / \pi$, and the influencing factor of corrosion depth is represented by $f(d / t)$, which is to be obtained by regression in the following part. Here, the expression of limit pressure of the corroded riser, $p_{\mathrm{b}}$, is given in Eq. (10).

$p_{\mathrm{b}}=\frac{4 \mathrm{e}^{-n} \sqrt{3^{-n} \mathrm{e}^{2 n} \pi^{2} t^{2} \sigma_{\mathrm{u}}^{2}(D-t)^{2}-F_{\mathrm{a}}^{2}}}{\sqrt{3} \pi(D-t)^{2}}\left(1-\frac{\alpha}{\pi}\right) f\left(\frac{d}{t}\right)$

In order to calculate the influencing factor of corrosion depth, $f(d / t)$, a finite element analysis is performed using commercial software, ABAQUS. First, a finite element model with given parameters (Table 1) is created with geometrical and material parameters. The riser model has only one layer, which is made of X60 steel. $\sigma_{\mathrm{y}}$ represents the yield strength and $\sigma_{\mathrm{u}}$ represents the tensile strength. The material characteristic is described by an elastoplastic model. Beyond the elastic range, the non-linear relationship between stress and strain satisfies the power-law principle (Eq. (1)), where the strengthening factor is set as 0.1 (Zhu and Leis, 2004). The riser is meshed by C3D8R full continuum eight node elements with reduced integration (see Fig. 2), which exhibit no shear locking and can decrease computing time.

Table 1 Parameters of the finite element model

\begin{tabular}{cccccccccc}
\hline Material & $\begin{array}{c}D \\
\mathrm{~mm}\end{array}$ & $\begin{array}{c}\alpha \\
\mathrm{rad}\end{array}$ & $\begin{array}{c}L \\
\mathrm{~mm}\end{array}$ & $\begin{array}{c}\sigma_{\mathrm{u}} \\
\mathrm{MPa}\end{array}$ & $\begin{array}{c}\sigma_{\mathrm{y}} \\
\mathrm{MPa}\end{array}$ & $\begin{array}{c}t \\
\mathrm{~mm}\end{array}$ & $\begin{array}{c}F_{\mathrm{a}} \\
\mathrm{kN}\end{array}$ & $\begin{array}{c}d \\
\mathrm{~mm}\end{array}$ & $n$ \\
\hline X60 steel & 508 & 0.0375 & 899 & 565 & 414 & 6.4 & 600 & 3.4 & 0.1 \\
\hline
\end{tabular}

The yielding status of the riser is different at different internal pressures. For material obeying the von Mises yield criterion, yielding failure occurs when the von Mises stress across the whole surface surpasses the reference strength. In

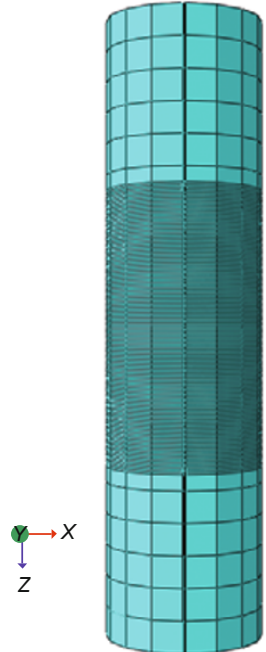

Fig. 2 Grid partition

this paper, the reference strength is set to be $0.9 \sigma_{\mathrm{u}}(508 \mathrm{MPa})$, as suggested by Chen et al (2008). In order to demonstrate the specific yielding status, the riser is partitioned by the $X-Y$ plane. Three types of yielding status, relating to three different internal pressures, are given.

Figs. 3-5 indicate that yielding occurs across the whole defect when the internal pressure is 7.0 MPa. In other words, 7.0 $\mathrm{MPa}$ is the limit pressure of the marine riser with this corrosion depth. Similarly, other limit pressures can be obtained in terms of different corrosion depths, listed in Table 2.

Table 2 Corrosion depth and the corresponding limit pressure

\begin{tabular}{cc||cc}
\hline$d, \mathrm{~mm}$ & $p_{\mathrm{b}}, \mathrm{MPa}$ & $d, \mathrm{~mm}$ & $p_{\mathrm{b}}, \mathrm{MPa}$ \\
\hline 3.4 & 7.0 & 1.9 & 11.0 \\
3.2 & 7.6 & 1.6 & 11.6 \\
2.9 & 8.6 & 1.3 & 12.3 \\
2.5 & 9.3 & 1.0 & 13.2 \\
2.2 & 10.2 & 0.6 & 13.2 \\
\hline
\end{tabular}

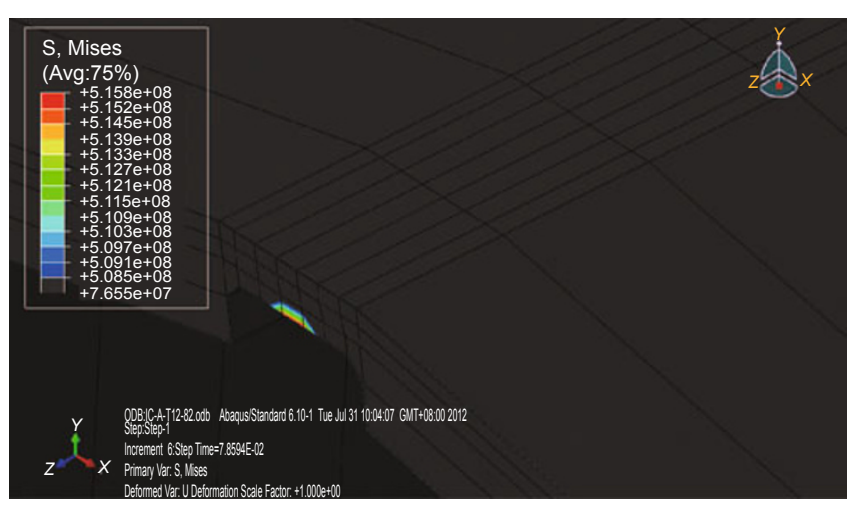

Fig. 3 Yielding status of corrosion defect when the internal pressure is $6.5 \mathrm{MPa}$

The influencing factor of the corrosion depth $(f(d / t))$ can be fitted with a parabolic curve, illustrated in Fig. 6. The limit pressure of the marine riser with a narrow long corrosion defect under axial force and internal pressure is given in Eq. (11). 


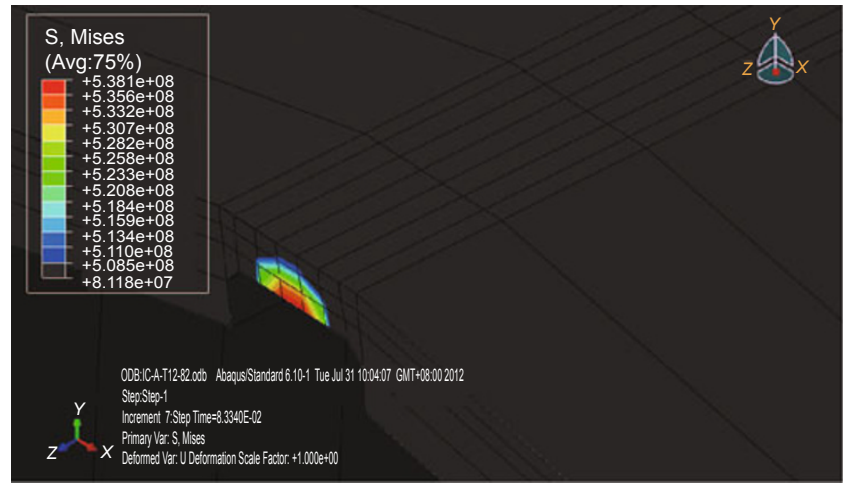

Fig. 4 Yielding status of corrosion defect when the internal pressure is $6.6 \mathrm{MPa}$

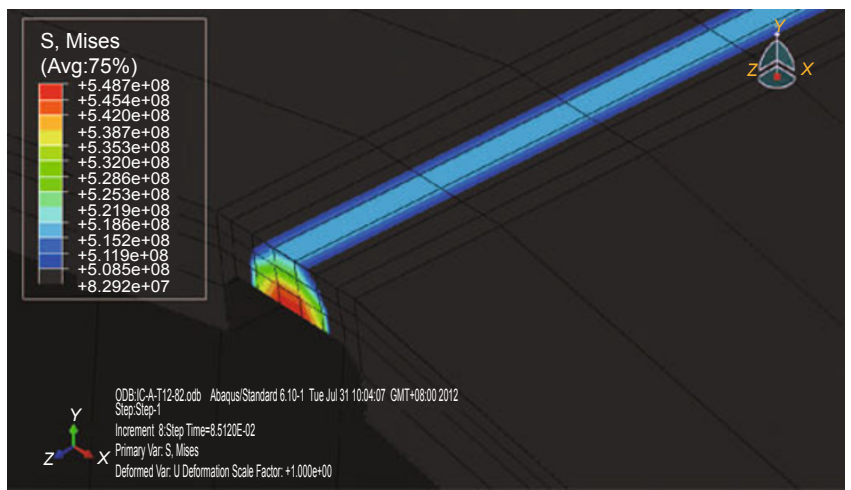

Fig. 5 Yielding status of corrosion defect when the internal pressure is $7.0 \mathrm{MPa}$

$$
\begin{aligned}
& p_{\mathrm{b}}=\frac{4 \mathrm{e}^{-n} \sqrt{3^{-n} \mathrm{e}^{2 n} \pi^{2} t^{2} \sigma_{\mathrm{u}}^{2}(D-t)^{2}-F_{\mathrm{a}}^{2}}}{\sqrt{3} \pi(D-t)^{2}} \times \\
& \left(1-\frac{\alpha}{\pi}\right)\left(-0.634\left(\frac{d}{t}\right)^{2}-0.549\left(\frac{d}{t}\right)+0.925\right)
\end{aligned}
$$

In order to verify the accuracy of the proposed function of limit pressure, the result obtained from the proposed function is compared with those obtained from ASME B31G, ASME M-B31G, DNV-RP-F101, Netto et al (2005), Leis and Stephens (1997) and finite element analysis (FEA). 15 cases are considered and the limit pressures obtained by FEA are listed in Table 3. The result of FEA is regarded as the standard limit pressure due to a lack of experimental data. The relative errors $\left(E_{\mathrm{r}}\right)$ are calculated as follows:

$$
E_{\mathrm{r}}=\frac{p_{\mathrm{i}}-p_{\mathrm{FEA}}}{p_{\mathrm{FEA}}} \times 100 \% \quad(i=1,2, \cdots, 6)
$$

where $p_{\mathrm{i}}$ is the results calculated with Eq. (11) and $p_{\mathrm{FEA}}$ is FEA results.

If $E_{\mathrm{r}}<0$, the limit pressure is conservative. On the other hand, if $E_{\mathrm{r}}>0$, the limit pressure is risky. According to the results illustrated in Fig. 7, the proposed function of limit pressure is the most accurate, which means Eq. (11) is most appropriate to calculate the limit pressure of marine risers with narrow and long corrosion defects under combined loads.

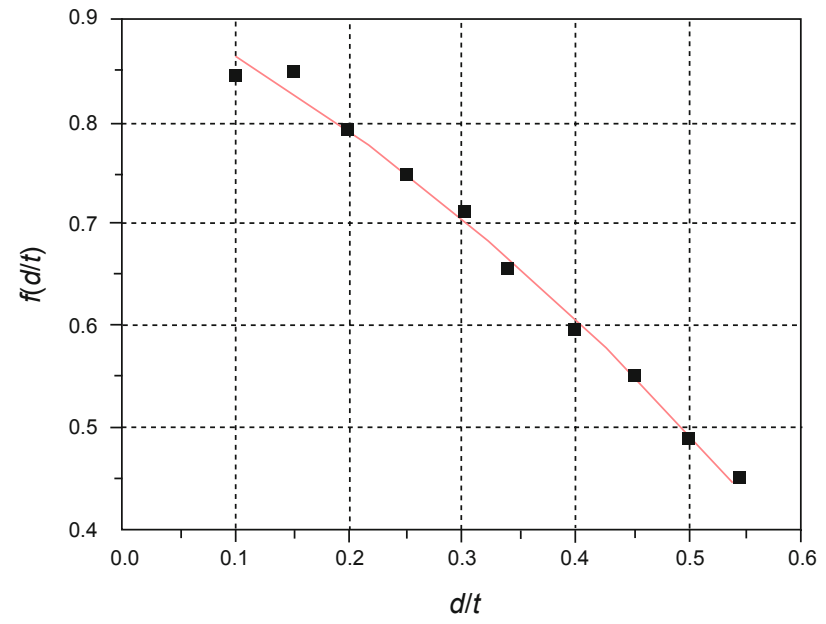

Fig. 6 Fitting of the influencing factor of the corrosion depth

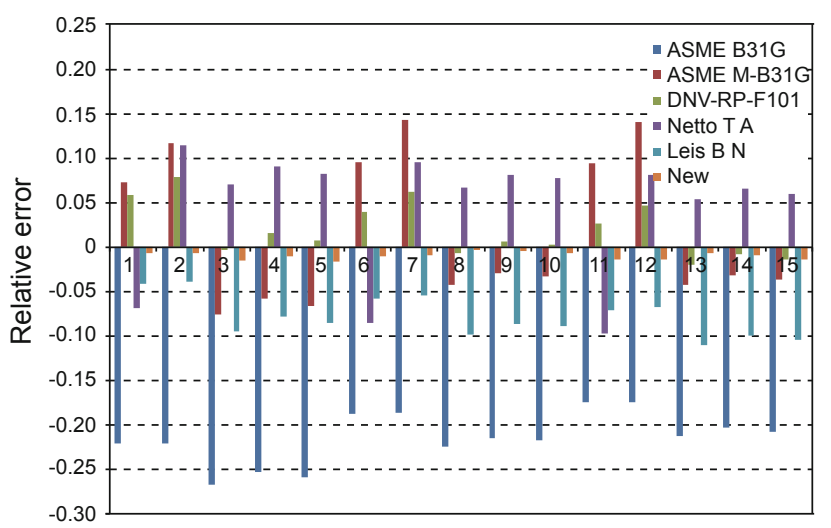

\begin{tabular}{|c|c|c|c|c|c|c|c|c|}
\hline No. & Steel parameters & $\begin{array}{c}D \\
\mathrm{~mm}\end{array}$ & $\begin{array}{c}t \\
\mathrm{~mm}\end{array}$ & $\begin{array}{c}L \\
\mathrm{~mm}\end{array}$ & $\begin{array}{c}d \\
\mathrm{~mm}\end{array}$ & $\begin{array}{c}\alpha \\
\mathrm{rad}\end{array}$ & $\begin{array}{c}F_{\mathrm{a}} \\
\mathrm{kN}\end{array}$ & $\begin{array}{l}p_{\text {FEA }} \\
\mathrm{MPa}\end{array}$ \\
\hline 1 & \multirow{5}{*}{$\begin{array}{c}\mathrm{X} 60 \\
\sigma_{\mathrm{y}}=414 \mathrm{MPa} \\
\sigma_{\mathrm{u}}=565 \mathrm{MPa}\end{array}$} & 508 & 6.4 & 1500 & 3.5 & 0.0386 & 700 & 6.5 \\
\hline 2 & & 508 & 6.4 & 1000 & 3.5 & 0.0386 & 700 & 6.5 \\
\hline 3 & & 508 & 6.4 & 1000 & 2.4 & 0.0386 & 700 & 9.5 \\
\hline 4 & & 508 & 6.4 & 1000 & 2.4 & 0.0827 & 700 & 9.4 \\
\hline 5 & & 508 & 6.4 & 1000 & 2.4 & 0.0827 & 600 & 9.4 \\
\hline 6 & \multirow{5}{*}{$\begin{array}{c}\text { X70 } \\
\sigma_{\mathrm{y}}=483 \mathrm{MPa} \\
\sigma_{\mathrm{u}}=621 \mathrm{MPa}\end{array}$} & 508 & 6.4 & 1500 & 3.5 & 0.0386 & 700 & 7.3 \\
\hline 7 & & 508 & 6.4 & 1000 & 3.5 & 0.0386 & 700 & 7.3 \\
\hline 8 & & 508 & 6.4 & 1000 & 2.4 & 0.0386 & 700 & 10.7 \\
\hline 9 & & 508 & 6.4 & 1000 & 2.4 & 0.0827 & 700 & 10.5 \\
\hline 10 & & 508 & 6.4 & 1000 & 2.4 & 0.0827 & 600 & 10.5 \\
\hline 11 & \multirow{5}{*}{$\begin{array}{c}\text { X80 } \\
\sigma_{\mathrm{y}}=552 \mathrm{MPa} \\
\sigma_{\mathrm{u}}=690 \mathrm{MPa}\end{array}$} & 508 & 6.4 & 1500 & 3.5 & 0.0386 & 700 & 8.1 \\
\hline 12 & & 508 & 6.4 & 1000 & 3.5 & 0.0386 & 700 & 8.1 \\
\hline 13 & & 508 & 6.4 & 1000 & 2.4 & 0.0386 & 700 & 12.0 \\
\hline 14 & & 508 & 6.4 & 1000 & 2.4 & 0.0827 & 700 & 12.0 \\
\hline 15 & & 508 & 6.4 & 1000 & 2.4 & 0.0827 & 600 & 12.0 \\
\hline
\end{tabular}

Fig. 7 Relative errors of different equations to FEA results

Table 3 Limit pressure obtained from finite element analysis 


\section{Reliability analysis}

The stress-strength model (see Eq. (13)) is employed to perform reliability analysis. Here, stress refers to the operating internal pressure $\left(p_{\mathrm{o}}\right)$ and strength refers to the limit pressure $\left(p_{\mathrm{b}}\right)$.

$$
\begin{aligned}
Z & =p_{\mathrm{b}}-p_{\mathrm{o}} \\
& =\frac{4 \mathrm{e}^{-n} \sqrt{3^{-n} \mathrm{e}^{2 n} \pi^{2} t^{2} \sigma_{\mathrm{u}}^{2}(D-t)^{2}-F_{\mathrm{a}}^{2}}}{\sqrt{3} \pi(D-t)^{2}}\left(1-\frac{\alpha}{\pi}\right) \times \\
& \left(-0.634\left(\frac{d}{t}\right)^{2}-0.549\left(\frac{d}{t}\right)+0.925\right)-p_{\mathrm{o}} \\
& =g\left(D, t, d, \alpha, \sigma_{\mathrm{u}}, F_{\mathrm{a}}, p_{\mathrm{o}}\right)
\end{aligned}
$$

If $Z>0$, the system is in the safe domain. If $Z=0$, the system is in the limit state. If $Z<0$, the system is the failure domain. In order to solve Eq. (13), the distribution of these random variables should be first obtained. Moreover, the failure probability, reliability index and sensitivity are calculated by the HL-RF algorithm. Finally, these results are verified by MCIS and the simulation times are optimized at the same time.

\subsection{Distribution of random variables}

Referring to the design and inspection data of a marine riser in an engineering project, random variables referred to structure resistance and load can be obtained, including $D$, $t, d, \alpha, \sigma_{\mathrm{u}}, F_{\mathrm{a}}, p_{\mathrm{o}}$. However, due to the complex and dynamic marine environment, the axial force can neither be detected, nor calculated. Therefore, FEA is employed to obtain the axial force through ABAQUS. The finite element model (see Fig. 8) is based on the engineering parameters, listed as follows.

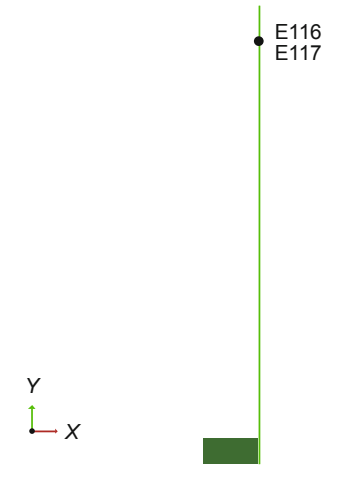

Fig. 8 Finite element model of the riser

The total length of the riser model is $95.7 \mathrm{~m}$, including 8.5 $\mathrm{m}$ in the air, $80.5 \mathrm{~m}$ in the ocean and $6.7 \mathrm{~m}$ under the seabed. The outer diameter and wall thickness are 508 and $6.35 \mathrm{~mm}$, respectively. API X-60 steel is used for the riser, with Young's modulus of $210 \mathrm{GPa}$, Poisson's ratio of 0.3 and density of $7,850 \mathrm{~kg} / \mathrm{m}^{3}$. The significant wave height and maximum wave height are 4.4 and $7.5 \mathrm{~m}$, respectively. The returning period of wave and current is 15 years. The significant wave period and maximum wave period are 6.9 and $8.8 \mathrm{~s}$. The surface layer, middle layer and bottom layer current speed are 1.77, 1.56 and $1.33 \mathrm{~m} / \mathrm{s}$, respectively. The horizontal and vertical soil rigidity are 18,060 and 9,150 N/m. The riser model has only one layer, which is simulated by beam elements. Besides, the soil model is simulated by pipe-soil-interactions (PSI) element.

The corroded region lies in the splash zone, being $2 \mathrm{~m}$ high above sea surface. The total length of the corroded region is $2 \mathrm{~m}$, which is partitioned into two parts, named E116 and E117. The results of the above FEA suggest that axial forces acting on E116 and E117 are very similar. Accordingly, a sample of 1,620 axial forces acting on E116 are selected, whose scatter diagram and frequency histogram are illustrated in Figs. 9 and 10. Through statistics analysis by commercial software, SAS (Rice, 2007; Gao, 2001), the value of Kolmogorov-Smirnov is 0.0169 and significant probability $P>0.15$, proving the normality of axial force distribution (Eq. (14)).

$$
F_{\mathrm{a}} \sim N\left(706069.527,176945.872^{2}\right)
$$

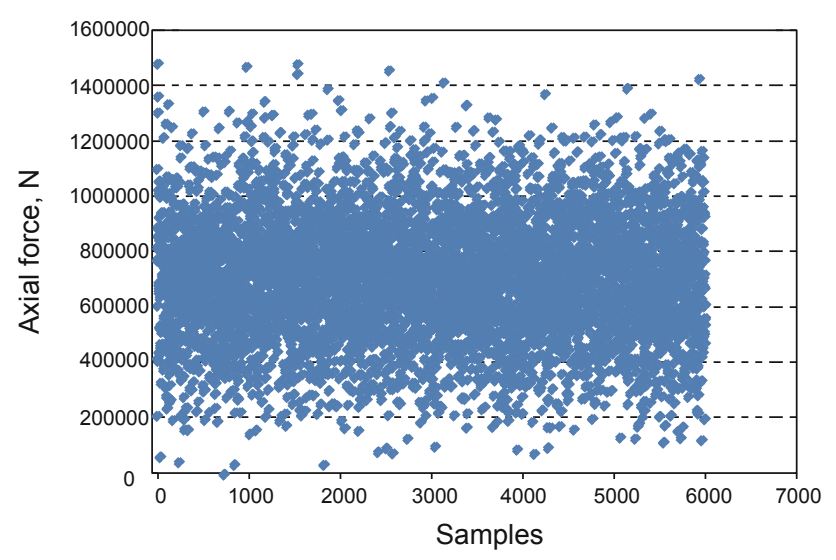

Fig. 9 Scatter plot of the axial force

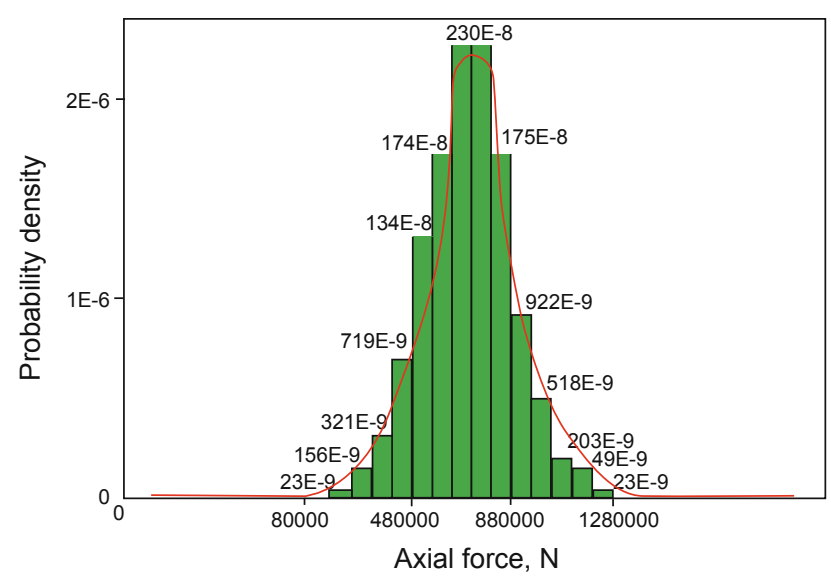

Fig. 10 Frequency histogram of the axial force

Similarly, the distribution of moment can be obtained. Also, the distribution characteristics of other random parameters of the riser and its defect can be directly obtained from the engineering project, listed in Table 4. 
Table 4 Parameter distribution

\begin{tabular}{cccccccccc}
\hline & $\begin{array}{c}D \\
\mathrm{~mm}\end{array}$ & $\begin{array}{c}t \\
\mathrm{~mm}\end{array}$ & $\begin{array}{c}d \\
\mathrm{~mm}\end{array}$ & $\begin{array}{c}\alpha \\
\mathrm{rad}\end{array}$ & $\begin{array}{c}\sigma_{\mathrm{u}} \\
\mathrm{MPa}\end{array}$ & $\begin{array}{c}F_{\mathrm{a}} \\
\mathrm{kN}\end{array}$ & $\begin{array}{c}M_{\mathrm{o}} \\
\mathrm{kN} \cdot \mathrm{m}\end{array}$ & $\begin{array}{c}p_{\mathrm{o}} \\
\mathrm{MPa}\end{array}$ \\
\hline Distribution & Normal & Normal & Lognormal & Lognormal & Normal & Normal & Normal & Normal \\
Mean & 508 & 6.4 & 2.5 & 0.0562 & 565 & 706.07 & 64.43 & 4.5 \\
COV (Coefficient of variation ) & 0.04 & 0.02 & 0.08 & 0.05 & 0.07 & 0.31 & 0.45 & 0.05 \\
\hline
\end{tabular}

\subsection{Reliability calculation through HL-RF algorithm}

The HL-RF algorithm (Hasofer and Lind, 1974; Rackwitz and Flessler, 1978) was employed to perform reliability calculations. The HL-RF algorithm is the advanced form, which is widely used due to its high efficiency (Koduru and Haukaas, 2010; Thorndahl and Willems, 2008; Yang, et al, 2006). It is formally recommended for engineering by the Joint Committee of Structural Safety (JCSS). In this paper, the HL-RF algorithm is employed to calculate the reliability index $(\beta)$, failure probability $\left(P_{\mathrm{f}}\right)$ and sensitivity $(\eta)$.

In the first step, the initial value of each most-probablefailure-point (MPFP, $P^{*}$ ) is set as the equivalent mean value of each variable: for the variables with normal distribution, the equivalent mean value is set as the mean value; for the variables with non-normal distribution, the equivalent mean value is calculated from the mean value (He and Wang, 1993). In this work, the corrosion depth $(d)$ and half of the corrosion angle $(\alpha)$ should be transformed into equivalent values. In addition, sensitivity ( $\eta$, Eq. (15)) and cosine of direction-angle ( $\lambda$, Eq. (16)) are calculated at MPFP. Based on the above values, the reliability index $(\beta)$ can be obtained by solving the limit state function (Eq. (14)). If the relative error between two adjacent indexes is bigger than $1 \times 10^{-6}$, re-calculate MPFP (Eq. (17)), $\eta$ and $\lambda$, with which the new index can be worked out. The above-mentioned steps will continue until the relative error between two adjacent indexes is smaller than $1 \times 10^{-6}$. Finally, the failure probability $\left(P_{\mathrm{f}}\right.$, Eq. (18)) is calculated.

$$
\begin{aligned}
& \eta_{i}=\frac{-\left(\partial g / \partial x_{i}\right)_{P^{*}}}{\sqrt{\sum_{i=1}^{n}\left(\partial g / \partial x_{i}\right)_{P^{*}}^{2}}} \\
& \lambda_{i}=\frac{-\left(\partial g / \partial x_{i}\right)_{P^{*}} \sigma_{x_{i}}}{\sqrt{\sum_{i=1}^{n}\left(\partial g / \partial x_{i}\right)_{P^{*}}^{2}}} \\
& x_{i}^{*}=\mu_{x_{i}}+\lambda_{i} \beta \sigma_{x_{i}} \\
& P_{\mathrm{f}}=\Phi(-\beta)
\end{aligned}
$$

The above procedure is implemented as a Matlab program, obtaining MPFP (Table 5) and sensitivity (Table 6) of each variable. The reliability index and failure probability are also worked out: the former is 2.70 and the latter is 0.0035 .
Table 5 MPFP result through HL-RF calculation

\begin{tabular}{ccccccc}
\hline$D, \mathrm{~mm}$ & $t, \mathrm{~mm}$ & $d, \mathrm{~mm}$ & $\alpha, \mathrm{rad}$ & $\sigma_{\mathrm{u}}, \mathrm{MPa}$ & $F_{\mathrm{a}}, \mathrm{kN}$ & $p_{\mathrm{o}}, \mathrm{MPa}$ \\
\hline 513.6 & 6.3 & 2.6 & 0.0561 & 518.94 & 733.14 & 4.6 \\
\hline
\end{tabular}

Table 6 Sensitivity result through HL-RF calculation

\begin{tabular}{ccccccc}
\hline$\eta_{D}$ & $\eta_{t}$ & $\eta_{d}$ & $\eta_{\alpha}$ & $\eta_{\sigma_{\mathrm{u}}}$ & $\eta_{F_{\mathrm{a}}}$ & $\eta_{p_{\mathrm{o}}}$ \\
\hline 5.011 & -7.81 & 782 & 0.874 & $-9.499 \times 10^{-9}$ & $2.094 \times 10^{-7}$ & $5.885 \times 10^{-7}$ \\
\hline
\end{tabular}

From above reliability calculation, some conclusions are summarized.

- In terms of marine risers with narrow and long corrosion defects under combined loads, the reliability index is 2.70 and the failure probability is 0.0035 . According to the code of Riser Integrity Management (DNV-RP-F206, 2008), the probability category is 4 (DNV-RP-F107, 2001).

- Corrosion depth and wall-thickness are two most sensitive factors. In particular, the former is positively correlated, meaning that the greater the value, the greater the risk will be. The latter is negatively correlated, which means that the smaller the value, the greater the risk.

- If the variables' values reach most-probable-failurepoint (MPFP), it is on the border of failure. In other words, MPFP is the critical point, which should be avoided.

\subsection{Reliability verification through MCIS}

MCIS is employed to perform reliability verification. As Monte Carlo simulation is always low in efficiency, the importance sampling procedure is employed to avoid this weakness (Campioni and Vestrucci, 2004; Levine, 1998; Berliner and Wikle, 2007). The principle of MCIS is to set the sampling center at MPFP, obtained from the HL$\mathrm{RF}$ algorithm. The sampling field is dynamically specified around the sampling center. Probability distributions of random variables are the same as those in Table 4. MCIS is implemented in Matlab, to obtain reliability index and failure probability for different numbers of samples (Table 7).

Table 7 Reliability verification through MCIS

\begin{tabular}{ccc}
\hline Samples & $\beta$ & $P_{\mathrm{f}}$ \\
\hline 100 & 2.6162 & 0.0044 \\
400 & 2.7016 & 0.0035 \\
900 & 2.6610 & 0.0039 \\
1600 & 2.6590 & 0.0039 \\
2500 & 2.6646 & 0.0039 \\
\hline
\end{tabular}


According to a comparison among the results obtained from different numbers of samples (see Fig. 11), 900, with the smallest error of both reliability index and failure probability, is accurate enough. Moreover, these results are very close to those obtained from HL-RF calculation, serving as a good verification.

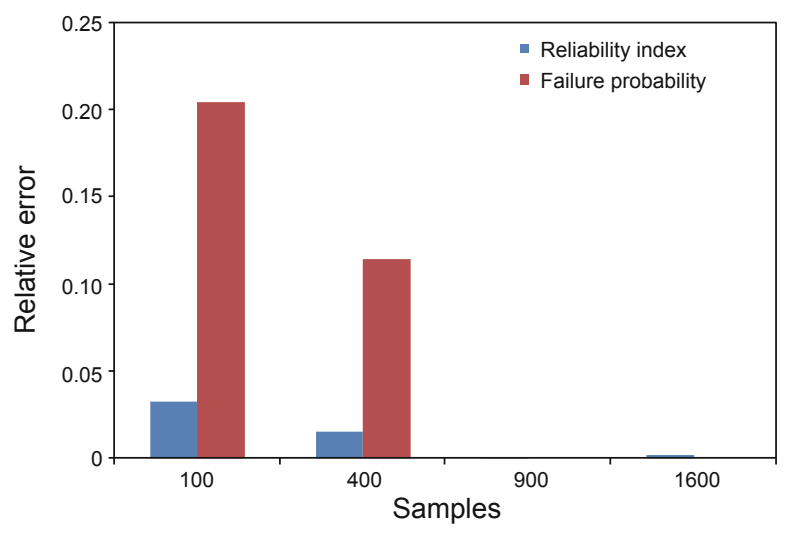

Fig. 11 A comparison among different numbers of samples

\subsection{Method comparison}

The HL-RF algorithm is of high efficiency in performing reliability calculation, which can accurately obtain MPFP, sensitivity, reliability index and failure probability. On the contrary, the Monte-Carlo simulation is of low efficiency, needing much more simulation time for large calculation (Sciuva and Lomario, 2003). In this work, the Monte-Carlo procedure cannot obtain an accurate solution even with 1 million iterations (see Appendix B). However, MCIS can greatly improve the efficiency of Monte-Carlo simulation. In this work, 900 simulations is enough to obtain an accurate result. Importantly, the sampling center of MCIS is set as the most-probable-failure-point (MPFP), which should be firstly obtained with the HL-RF algorithm in this method.

Generally, the HL-RF algorithm is an accurate method to calculate reliability, and MCIS is an efficient way to perform reliability verification. Thus, a combined application of the HL-RF algorithm and the MCIS method is both accurate and efficient in reliability analysis.

\section{Conclusions}

A new approach of reliability analysis is proposed for marine risers with narrow and long internal corrosion defects under combined loads. Conclusions are summarized as follows:

1) The proposed analytical-numerical function gives more accurate results in analyzing the limit state of marine risers with narrow and long corrosion defect under combined loads, compared to those in ASME B31G, ASME M-B31G, DNVRP-F101, Netto et al (2005) and Leis and Stephens (1997).

2) The reliability index of 2.70 and the failure probability of 0.0035 are calculated and verified, suggesting that the probability category is 4 (DNV-RP-F107, 2001). Corrosion depth and wall-thickness are identified as the two main sensitive factors.

3) The HL-RF algorithm is an accurate method to calculate reliability, and the MCIS method is an efficient way to perform reliability verification. A combination of the HL-
RF algorithm and the MCIS method can be a comprehensive solution for the reliability analysis of internal corroded risers.

\section{Acknowledgements}

We thank the National Basic Research Program of China (973 Program, Grant No. 2011CB013702) and the Beijing Natural Science Foundation (Grant No. KZ201210017017). The authors would also like to express great appreciation for the critical reviews from Prof. Zhou Jing and Prof. Li Xin of the Dalian University of Technology.

\section{References}

Ahammed M and Melchers R E. Reliability estimation of pressurized pipelines subject to localized corrosion defects. International Journal of Pressured Vessel and Piping. 1996. 69(3): 267-272

Amirat A, Mohamed-Chateauneuf A and Chaoui K. Reliability assessment of underground pipelines under the combined effect of active corrosion and residual stress. International Journal of Pressure Vessels and Piping. 2006. 83(2): 107-117

API-579-1/ASME FFS-1. Fitness-for-Service. American Petroleum Institute. 2009. 7-9

ASME B31G. Manual for Determining the Remaining Strength of Corroded Pipelines, a Supplement to ANSI/ASME B31 Code for Pressure Piping. ASME. 2009. 5-8

Berliner L M and Wikle C K. Approximate importance sampling Monte Carlo for data assimilation. Physica D: Nonlinear Phenomenon. 2007. 230(1-2): 37-49

BS-7910. Guide on Methods for Assessing the Acceptability of Flaws in Metallic Structures. British Standard. 1999. 5-100

Caleyo F, Gonzalez J L and Hallen J M. A study on the reliability assessment methodology for pipelines with active corrosion defects. International Journal of Pressured Vessel and Piping. 2002. 79(1): 77-86

Campioni L and Vestrucci P. Monte Carlo importance sampling optimization for system reliability applications. Annals of Nuclear Energy. 2004. 31(9): 1005-1025

Chen Y F, Li X, Jin Q, et al. Burst capacity solutions for submarine pipeline with long corrosion defects. Proceedings of the 18 th International Offshore and Polar Engineering Conference, International Society of Offshore and Polar Engineers (ISOPE), 2008, Vancouver, BC, Canada

DNV-RP-F101. Corroded Pipeline. Det Norske Veritas, 2004. 14-20

DNV-RP-F107. Risk Assessment of Pipeline Protection. Det Norske Veritas, 2001. 31-35.

DNV-RP-F206. Riser Integrity Management. Det Norske Veritas, 2008: $52-55$

Gao H X. Statistic Methods and SAS system. Beijing: Peking University Press. 2001. 14-39 (in Chinese)

Hasofer A M and Lind N C. Exact and invariant second-moment code format. ASCE Journal of Engineering Mechanics Division. 1974. 100(1): 21-111

He S Q and Wang S. Study on the Analysis and Design Based on Structure Reliability. Beijing: National Defense Industry Press. 1993. 20-103 (in Chinese)

Kiefner J F and Vieth P H. A modified criterion for evaluating the remaining strength of corroded pipe. Battelle Columbus Div., $\mathrm{OH}$ (USA): Pipeline Research Committee, American Gas Association. 1989. 1-126

Koduru S D and Haukaas T. Feasibility of FORM in finite element reliability analysis. Structural Safety. 2010. 32(2): 145-153

Leis B N and Stephens D R. An alternative approach to assess the integrity of corroded line pipe, part II-alternative criterion. Proceedings of the Seventh International Offshore and Polar 
Engineering Conference. 1997. 624-641. Honolulu, USA

Levine R D. Monte Carlo, maximum entropy and importance sampling. Chemical Physics. 1998. 228(1-3): 255-264

Maes M A, Mann M and Salama M M. Influence of grade on the reliability of corroding pipelines. Reliability Engineering \& System Safety. 2007. 93(3): 448-454

Muhlbauer W K. Pipeline Risk Management Manual (2nd Ed.). Gulf Publishing Company. 1996. 1-356

Netto T A, Ferraz U S and Estefen S F. The effect of corrosion defects on the burst pressure of pipelines. Journal of Constructional Steel Research. 2005. 61(8): 1185-1204

Nuhi M, Seer T A and Al Tamimi A M. Reliability analysis for degradation effects of pitting corrosion in carbon steel pipes. Procedia Engineering. 2011. 10: 1930-1935

Rackwitz R and Flessler B. Structural reliability under combined randomload sequences. Computers \& Structures. 1978. 9(5): 489494

Rice J A. Mathematical Statistics and Data Analysis (3rd Ed.). Berkeley: University of California Press. 2007. 255-376

Sciuva M D and Lomario D. A comparison between Monte Carlo and FORMs in calculating the reliability of a composite structure. Composite Structures. 2003. 59(1): 155-162

Teixeira A P, Soares C G, Netto T A, et al. Reliability of pipelines with corrosion defects. International Journal of Pressured Vessel and Piping. 2008. 85(4): 228-237

Thorndahl S and Willems P. Probabilistic modelling of overflow, surcharge and flooding in urban drainage using the first-order reliability method and parameterization of local rain series. Water Research. 2008. 42(1-2): 455- 466

Yang D X, Li G and Cheng G D. Convergence analysis of first order reliability method using chaos theory. Computers and Structures. 2006. 84(8-9): 563-571

Zhou W X. System reliability of corroded pipelines. International Journal of Pressure Vessels and Piping. 2010. 87(10): 587-595

Zhu X K and Leis B N. Strength criteria and analytic predictions of failure pressure in line pipes. International Journal of Offshore and Polar Engineering. 2004. 14(2): 125-131 (paper ISOPE: 04-14-2125)

\section{Appendix A: Influence of moment}

The influence of moment is simulated by commercial software, ABAQUS, whose model is the same as the one in Section 2.2 (Fig. 2). The riser is subjected to three types of loads: internal pressure, axial force and moment. These loads are set as their mean values, which are obtained from FEA in Section 3.1 (Table 4). In other words, the internal pressure is $4.5 \mathrm{MPa}$, the axial force is $706 \mathrm{kN}$, and the moment is $64.4 \mathrm{kN} \cdot \mathrm{m}$. If the model is subjected to two combined loads, say internal pressure and axial force, the von Mises stress is shown in Fig. A1; if the model is subjected to three combined loads, say internal pressure, axial force and moment, the von Mises stress is shown in Fig. A2.

\section{Appendix B: Monte-Carlo simulation}

The basic Monte-Carlo procedure is employed to calculate the reliability of internal corroded risers. The seven random variables in the limit state function (Eq. (13)) are sampled in the feasible region rather than around MPFPs. This leads to high uncertainties in sampling and causes inaccurate outcomes with limited samples. According to Table B1, although sampling 1 million times, the results are not convergent and accurate compared with those obtained by MCIS (see Table B1).
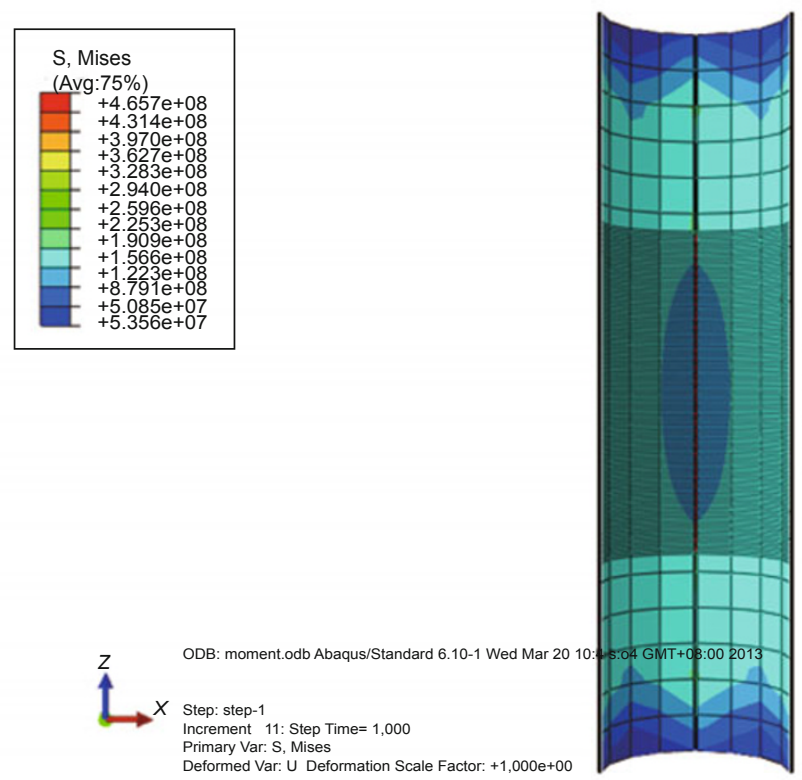

Fig. A1 Von Mises stress under internal pressure and axial force (inner section)

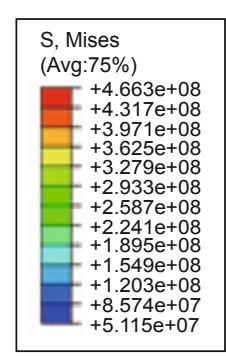

Step: step-1 Increment 11: Step Time= 1,000 Primary Var: S, Mises

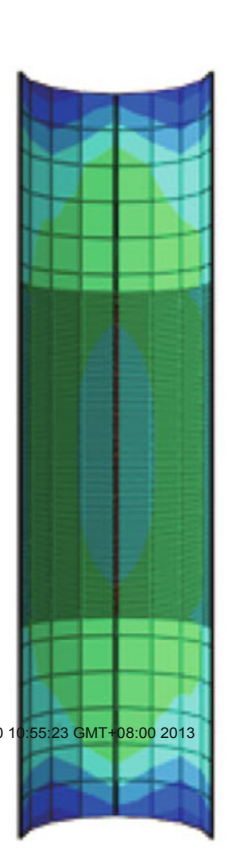
Increment 11: Step Time $=1,000$
Primary Var: S: Mises
Deformed Var: U Deformation Scale Factor: $+1,000 e+00$

Fig. A2 Von Mises stress under internal pressure, axial force and moment (inner section)

Table B1 Monte-Carlo simulation

\begin{tabular}{ccc}
\hline Samples & $\beta$ & $P_{\mathrm{f}}$ \\
\hline $1.0 \times 10^{4}$ & -0.3292 & 0.6290 \\
$2.5 \times 10^{5}$ & 0.1509 & 0.4400 \\
$4.9 \times 10^{5}$ & -0.0405 & 0.5161 \\
$6.4 \times 10^{5}$ & -0.1771 & 0.5703 \\
$8.1 \times 10^{5}$ & 0.5988 & 0.2747 \\
$1 \times 10^{6}$ & -0.6682 & 0.7480 \\
$1 \times 10^{6}$ & 0.1594 & 0.4367 \\
$1 \times 10^{6}$ & -0.2491 & 0.5984 \\
\hline
\end{tabular}

(Edited by Sun Yanhua) 